\title{
Examining Narrative Roles in Suicide Notes
}

Greyson S., Tzani-Pepelasi C., Pylarinou, R N., loannou, M. \& Artinopoulou V. (2020). Examining Narrative Roles in Suicide Notes. Journal of Investigative Psychology and Offender Profiling.

Accepted on the $2^{\text {nd }}$ of Feb, 2020.

\begin{abstract}
The present study examines suicide notes, using a sample of suicide notes from published corpora $(N=50)$, combined with a sample of recent suicide notes from a suicide website $(N=50)$. The present study proposes a model of differentiation in completed suicides. The characteristics of the suicide notes were analysed using a content dictionary developed by Giles in 2007, and the data subjected to Smallest Space Analysis. Four themes of suicide completer were discovered: Egoistic Victim, Anomic Hero, Altruistic Professional and Fatalistic Revenger. The implications of these findings and the potential use in therapy work with suicide survivors and those with suicidal ideation are discussed, as well as suggestions for the direction of future research.
\end{abstract}

Key Words: Narratives; Victim; Hero; Professional; Revenger. 


\section{Introduction}

Suicide is a global phenomenon. There are indications that for each adult who has died by suicide there could be more than 20 others attempting suicide (World Health Organization [WHO], 2016). In 2017 there were 5,821 deaths by suicide in the UK, with men being three times more likely to take their own lives than women (Samaritans, 2018). Suicide was defined by Shneidman (1993) as an 'act of self-induced annihilation, best understood as a multidimensional malaise in a needful individual who defines an issue for which suicide is perceived as the best solution'. Research into suicide notes can provide information on the thoughts and feelings of the suicidal individual (Callanan \& Davis, 2009; Cerel, Moore, Brown, van der Venne, \& Brown, 2014; Stack \& Rockett, 2016).

\subsection{Suicide note research}

Research on suicide notes have used the Linguistic Inquiry and Word Count (LIWC) program which is used to analyse suicide notes and their content. It was originally developed as part of an exploratory study of language and disclosure (Pennebaker, 1993) and has been recently updated (Pennebaker, Boyd, Jordan, and Blackburn 2015). The program has been widely used to explore linguistic and psychological differences in suicide notes for suicidal and non-suicidal individuals (Kim, Choi, Lee \& Sea 2019; Lee \& Joh 2019; Niederkrotenthalera, Tilla, Garciab, 2019).

Most of the existing research into suicide that uses note analysis has concentrated on distinguishing between genuine notes and fake ones, originating from the work of Shneidman and Farberow (1957). Suicide note research provides useful thematic discoveries, though sample sizes are often unrepresentative and methodologically unsound (McClelland, Reicher \& Booth, 2000). Studies often rely upon the same small sample of notes that were originally collected by 
Shneidman and Farberow (Sanger \& McCarthy Veach, 2008). Further criticism on the note analysis is that it provides an idiographic perspective (O'Connor Sheehy, \& O'Connor,1999). Simple content analysis such as noting that a word appears frequently offers little useful insight (Chávez-Hernández, Leenaars, Chávez-de-Sánchez \& Leenaars, 2009).

Despite the critique for content analysis, it provides a useful basis to examine the commonly occurring themes in suicide notes. Well documented work on thematic analysis has aided the construction of content dictionaries, such as the one produced by Giles (2007) and adapted by others (see Ioannou \& Debowska, 2014 \& Synnott Ioannou, Coyne, \& Hemingway, 2017). Giles (2007) postulates that at the core of all suicide notes exists an 'apologetic framework' in which a full narrative identity can be elucidated beyond the dominant narrative of saying sorry. These social and normative frames of reference mean that suicide notes can be viewed as ultra-social as well as ultra-personal documents — the latter described originally by Leenaars (1998). Accordingly, similar findings centered around apologies were found in an earlier study by Jacobs (1967). In this research Jacobs (1967) also found notes of direct accusation, which contained self-mitigation and no apologies. There were also notes that were structured as the last will and testament or instruction notes, which were concerned only with the logistics of funeral and finances.

Through their study of discourse analysis, McClelland, Reicher, and Booth, (2000) suggested that, in an attempt to express agency or power, suicide notes are written with the purpose of apportioning blame to the self or others, even to self-mitigate or mitigate others for the suicide. Their analysis of suicide notes $(N=172)$ from a coroner revealed references to blame in $87 \%$ of all notes. However, by their own admission, and in line with Gottschalk and Gleser (1960), McClelland et al (2000) highlight that there is a lack of evidence that people who leave 
suicide notes are representative of those who do not, or indeed of those whose suicide attempts are not successful. As this study focused solely on the interpersonal issue of assigning and managing blame, it may also have failed to discover other interpersonal themes (Sanger \& McCarthy Veach, 2008).

Adopting the (1957) corpus of Shneidman and Farberow, Ioannou and Debowska (2014) subjected genuine $(N=33)$ and simulated $(N=33)$ suicide notes to smallest space analysis. Deriving variables for analysis from the content dictionary of Giles (2007) their study established the themes of positive affect and self-blame, negative affect and self-mitigation, lack of self-acceptance and planned escape. The findings of McClelland, et al (2000) stated that, completed suicides were often concerned with blame management, with a particular emphasis on self-mitigation.

Synnott et al (2017) noted that completed suicides were more inclined to combine negative self-image with a concern for others. They found, in line with Durkheim (1951), support for all four suicide types, with the majority fitting with egoistic and anomic suicide, followed by fatalistic, though very few fitted with altruistic suicide.

Choosing to examine the presence of power or 'agency' in suicide notes, Langer Scourfield, and Fincham, (2008) discovered that people were concerned with minimising their own agency as a form of self-mitigation. In respect of the presence of agency, for the suicidal individual, taking his or her own life was a way to exert power over circumstances or forces beyond their control.

\subsection{Suicidology}

Reynolds and Berman (1995) in their empirical typology of suicide stated that the are more than a dozen typologies of suicide that are being reported in the literature (Ellis, 1988; 
Lester, 1994) that describe over 100 subtypes, two of the most prominent are Durkheim's and Baechler's. Durkheim (1951) distinguished four types of suicide based on polar positions on the axes of social integration and the social regulation these are egoistic, altruistic, anomic, and fatalistic. Baechler (1979) tried to distinguish four broad categories based on the logic of the suicidal individual rather than the motivation of the action. These are escapist, aggressive, oblative, and ludic. In suicide note research Durkheim has been used (Synnott et al 2017), whilst the Baechler typology has been used for suicide research and the motivates for self-harm (Abbas, Mohanna, Diab, Chikoore, \& Wang, 2018).

Durkheim (1951) as part of a model of social theory and in an attempt to explain the differences in suicide rates, researched and established four types of suicide, which he deemed 'ideal types'. Egoistic suicide occurs as a result of low social integration, or 'excessive individualism', where a person feels unsupported or the outsider in a group. This isolation, particularly in times of great stress, can lead individuals to perceive themselves as alone in the world. Altruistic suicide is the result of high social integration. The motivation for this type of suicide is adherence to the norms and values of a given group. As a form of martyrdom, the individual neglects their own needs and takes their own life for a cause, e.g., terrorism.

Fatalistic suicide is the result of a high degree of regulation, where an individual is subject to extreme rules and unrealistic expectations. As a result of this lack of freedom or autonomy, the individual loses their sense of self. Anomic suicide refers to a low degree of regulation and occurs when life is deprived of any sense of meaning, caused by maladjustment to traumatic events. The individual becomes extremely frustrated by being unable to conquer obstacles or set attainable goals (WordPress, 2011).

\subsection{Narrative approach}


According to McAdams and McLean (2013), narrative identity is the life story of a person, which is key to their individuality and evolves based upon reconstructions of past events and a perceived vision of the future. These narratives, that people apply to themselves, serve to give their life a sense of meaning and uniqueness, and are shaped by peoples' experiences throughout their life span. The key differences between individuals are the different themes which encompass their narrative stories, made up of characters, plots and themes. He describes 'imagoes' such as the escapist, survivor, warrior or sage, which are the very embodiment of the self or the 'me'. These imagoes act as a protagonist in the narrative, connected to the needs for agency or power, and communion or intimacy.

Agency is the extent to which a protagonist can affect change in their own life or have an influence on others - in effect, controlling their fate by demonstrating mastery of their environment, high achievement or enhanced status (McAdams \& McLean, 2013). Communion is concerned with the experience of interpersonal connectedness, through either friendship, love or connection to a group. This construct therefore personifies intimacy and belonging.

Canter (1994), used narrative theory to examine criminal behavior and suggested that criminal activity is best understood through analysis of the stories or 'inner narratives' of individuals (Canter \& Youngs, 2009). He also proposed that the role an offender assigns to the victim within the commission of an offence will be the result of their desire to achieve power or intimacy (Youngs \& Canter, 2009).

The core narratives underpin the roles that an offender acts out during an offence: revenger, victim, professional and hero, and the role that the offender assigns to his victim: person, vehicle, or object (Youngs \& Canter, 2009). Within the tragedy narrative, the offender adopts the role of somebody who has been unfairly treated and has no option but to avenge this 
wrong. Thus, the role here is revenger. Within this narrative the victim of the crime is viewed as a vehicle through which the offender can express anger. The victim may have symbolic significance within the life story of the offender.

In the irony narrative, the role of the offender is meaningless and senseless. This powerlessness renders them a victim. Within the offence in this narrative, the role assigned to the victim is that of a person, given full recognition by the offender and used for the purpose of abuse, as though it were a normal course of action. The adventure narrative sees the criminal role as that of a competent professional with their emotions in check, able to master their environment for reward and satisfaction. Here, the victim is an object, with very little human significance. The offender in the quest narrative is one on a mission, seeking to impose his will on situations in a bid to demonstrate his prowess by conquering challenges and salvaging his honour. The offender is therefore the hero. As with the tragedy narrative, the victim in the quest narrative is also that of a vehicle.

Youngs and Canter $(2011 ; 2012)$ applied this narrative structure in research with offenders using a case study interview approach and a narrative roles questionnaire, with a hypothesis that the crime narratives would expose roles in relation to the personal perception of the offender as strong or weak. Agency as discussed by McAdams (1985) was termed potency and communion termed intimacy, with the authors highlighting that potency in a criminal context relates to the exerting of the offender's will, so taking charge in the case of high potency as opposed to being passive when potency is low. Low potency in offending reveals the assigning of responsibility to others, expressed through helplessness and confusion, ascribing circumstances to fate and using expressions of constriction. In respect of intimacy, the researchers posit that high levels of intimacy reveal an offending style in which there is a good 
understanding of the victim and a motivation to have an effect on them, though the cognitive distortions present in relation to harm are ignored in favour of the offender achieving their objective (Youngs \& Canter, 2012).

In Youngs and Canter's (2011) study, the findings were as follows: within the quest narrative, high potency and high intimacy was apparent (revengeful mission role); within the tragedy narrative, low potency and low intimacy (tragic hero role); in the adventure narrative, high potency and low intimacy (professional role); and in the irony narrative, low potency and high intimacy (victim role). In a subsequent study, Youngs and Canter (2012) - through the use of narrative roles questionnaire based on interviews with 38 offenders detailing a range of offences - found cognitive interpretations revealing high potency/high intimacy in the narrative offence role of hero, rather than revenger; and low potency/low intimacy within the narrative role of revenger rather than hero. Their other findings did support those of their previous study in respect of associated levels of high/low agency and intimacy within the professional and victim roles.

A model of criminal narrative experience was created by Ioannou, Canter and Youngs (2017) based on an investigation of the emotions and narrative roles that offenders experience in the commission of a range of offences. Using the mentioned narrative roles questionnaire and an emotions questionnaire, the researchers delineated four separate narrative experience themes: Elated Hero, Calm Professional, Distressed Revenger and Depressed Victim. The Elated Hero was characterised by emotions such as exhilaration, excitement, manliness and courage. The Calm professional was more measured, relaxed, contented; all in a day's work. The Distressed Revenger depicted fear, anger and retaliation, whilst the Depressed Victim described helplessness, misery, constriction and inevitability. 
Criminal Narratives have been used over the years to explore different subjects such as control methods of victims of human trafficking for sexual exploitation (Ioannou \& Oostinga, 2015), young offenders (Ioannou, Synnott, Lowe, \& Tzani-Pepelasi, 2018), offenders with Psychopathic and Personality Disordered Offenders (Goodlad, Ioannou \& Hunter, 2019) and women offenders (Ciesla, Ioannou \& Hammond, 2019). Canter's (1994) criminal narratives and Durkheim's (1951) four model of "Ideal" suicide have some similarities in their categories. More specifically, Egoistic and Victim are both connected over the individual feeling alone within the world and having negative emotions. The Anomic and the Hero where the individual loses sense of control and "acts out", it is their way to regain their "honour". The Fatalist and the Revenger is characterised by the individual having a lack of sense of self and his in this situation due to others and must carry out this behaviour because the individual believes they had no other choice. The Altruistic and the Professional, in both these categories the individual is calm collected, the involvement in a social group is high and the expectation for a sacrifice are also high, for example suicide bombers.

\subsection{The present study}

Previous research using suicide notes has not linked suicide with narrative roles, but if there is value in linking an actor to their actions in a criminal context (Ioannou, et al, 2015), there is also possible relevance in doing so in the context of suicide. It is proposed that understanding the inner narrative of a suicidal individual can provide useful insight into the intention to act (Canter, 1994, Youngs \& Canter, 2011, 2012), just as it can for an offender.

The current study is exploratory in nature and aims to examine the potential of creating a model of differentiation in completed suicides based upon the content of their suicide notes. 
Using Multidimensional Scaling (MDS), the first objective is to explore whether suicide note content can be differentiated into narrative roles and the second objective is to determine if these roles align broadly with the suicide types proposed by Durkheim (1951).

\section{Method}

\subsection{Sample}

One hundred suicide notes were used for analysis. Thirty-three genuine suicide notes were utilised from the corpus of Shneidman and Farberow (1957), 17 suicide notes (female note section) from the corpus of Leenaars (1998) and 50 online suicide notes (dated 2013-2016) from The Suicide Project website ('My Suicide Note' section). Suicidal individuals frequently use this website to participate in discussions about suicide and share their suicide notes. All suicide notes used were freely accessible and all details kept anonymous.

\subsection{Procedure}

Content analysis on the notes was carried out using the adapted content dictionary produced by Ioannou and Debowska (2014), which was based on the original by Giles (2007). The adapted dictionary contains 74 variables. The variables are divided into six sections: practical features of the notes, constructing suicide and the decision to die, constructing explanation for suicide, constructing self, constructing others and structure of the notes. As per Giles' (2007) instructions on use of the dictionary, all suicide notes were divided into thought units which were analysed and coded according to their function within the text; in essence, examining what the writer achieves by using the word or phrase within their note. All data was coded dichotomously $(1=$ present, $0=$ absent $)$.

Using the same procedure as Synnott, et al (2017), who also used notes from the Suicide Project website in order to analyse notes from completed suicides, it was assumed that the 
suicide attempt was successful if no entry had been made in the suicide note section in the two years following the entry posting the suicide note.

\subsection{Analysis}

Once content analysis was complete and entries coded, the data was analysed using Smallest Space Analysis or SSA (Lingoes, 1973), which is a non-metric, multi-dimensional scaling procedure. SSA facilitates the examination of relationships by testing the co-occurrence of each variable with every other variable, the null hypothesis being that the variables have no visible relationship to each other. The strength of SSA is its use of rank orders of co-occurrences as rank orders of distances in the geometric space (Ioannou \& Debowska, 2014) and it has been used with success in a number of studies explicating themes (see Canter \& Fritzon, 1998; Fritzon \& Garbutt 2001; Salfati, 2000; Youngs \& Ioannou, 2013; Ioannou \& Oostinga, 2015; Ioannou, Hammond \& Simpson, 2015; Youngs, Ioannou \& Eagles, 2016; Ioannou, Synnott, Reynolds \& Pearson, 2018; Yaneva, Ioannou, Hammond \& Synnott, 2018).

In SSA the co-occurrence of variables is represented as Euclidean distances in the geometric space, as the geometric representation of relationships is easier to determine in a visual context than it would be to try to interpret the raw data. Association coefficients between all variables are computed by the SSA programme and these coefficients create a representation of items in the space. Each point represents a variable used - so, for example in this case, whether a note writer expressed anger, mentioned regret or left funeral instructions.

The more frequently the variables co-occur, the closer the points will be that represent those variables in the SSA space and, similarly, the further the distance between two points, the lower the association between those variables. Regions can subsequently be identified in the 
space, labelled and thematic structures delineated, though there is no mathematically precise position for the lines used to create regions (Youngs \& Canter, 2012).

Jaccard's coefficient was used as the measure of co-occurrence of variables. This method measures the number of co-occurrences between any two variables as a proportion of all occurrences of both variables (Ioannou \& Debowska, 2014, Synnott, et al, 2017). Variables with similar themes are expected to be found in the same region of the SSA space, allowing for hypothesis testing. The coefficient of alienation specifies how closely the co-occurrences in the matrix match the spatial representation of points on the SSA plot. The SSA was used to examine the co-occurrences of content variables from the suicide notes, in order to test the hypothesis that the characteristics of the notes can be separated into themes.

\section{Results}

An SSA analysis was performed on all suicide notes collectively $(N=100)$. The coefficient of alienation of .17 in 40 iterations indicates a good fit of the spatial representation of co-occurrences of the variables. The regional hypothesis states that variables sharing a common theme will be located within the same region of the SSA space (Ioannou \& Debowska, 2014). Visual examination of the plot reveals that it can be divided into four separate themes or regions linked to potency and intimacy, as shown in Figure 1.

\section{Place Figure 1 here with the accompanying caption (see separate sheet at the end of this document)}

Subsequently, themes of Egoistic Victim, Anomic Hero, Altruistic Professional and Fatalistic Revenger, are presented in Figure 2. 


\section{Place Figure 2 here with the accompanying caption (see separate sheet at the end of this document)}

As figure 2 above illustrates, regions of high/low potency and high/low intimacy are matched to the corresponding narrative roles of victim, revenger, hero and professional (Youngs \& Canter, 2011) and incorporate the four suicide themes proposed by Durkheim (1951) to create four narrative roles in completed suicides: Egoistic Victim, Anomic Hero, Fatalistic Revenger and Altruistic Professional.

\subsection{Egoistic Victim theme}

This theme implies low potency and high intimacy and contains the greatest number of content variables of any of the four themes $(N=37)$. The theme corresponds with the social isolation described in egoistic suicide by Durkheim (1951) and disconnectedness and despair described by Youngs and Canter (2011) in the victim narrative role. In this narrative theme, the suicide note writer fits the victim role of 'person', in full recognition that they are human (Canter, 1994).

The content characteristics of this theme are a mix of constructing suicide and the decision to die, explanations for suicide, constructing the self and constructing others. The high number of references to other people, irrespective of whether those people are viewed positively or negatively, indicates the significance of others and the need for the individual to connect with others through their suicide note. Items such as discover (v3) and conceal (v16) illustrate a desire on the part of the writer to protect others from what they might find or from what others might learn about how their life ended - thus they attempt to minimise the hurt or pain caused to others. Asking others to understand (v55), to not think badly of them (v68) offering apologies (v54), 
assigning no blame (v57), mitigating their partner (v63) and mitigating others (v60) are indicative of the desire to make amends with others in the face of death, along with the importance of saying goodbye (v66).

Other people are significant - whether perceived positively, negatively or a mixture of both - in this region as shown through variables such as mixed (v71), posother (v58), and negother (v59). In the posother variable, the writer positively constructs others (not including their partner) and in the negother variable, they negatively construct those other than their partner. Other indicators of high intimacy are asking to be remembered (v37) and asking those left behind to care for loved ones (v6). The explanations for suicide in this theme are also congruent with relationship issues and breakdowns, as illustrated by variables such as elablove (v48) and relation (v27).

The writers in this theme demonstrate through the content of their notes a perceived lack of potency or control through their references to loneliness (v31), to suicide as their only option (v17) and suicide as a means of escape from life or pain (v10). It is also implied here that there are circumstances or events which are perhaps beyond the writer's control (v42) and the longevity of their problems or suffering (v44). Other characteristics implying low potency are references to financial problems (v28), to giving of their own life to benefit others i.e. being a martyr (v64), avoidance of future events (v20) and a negative construction of self (v50).

\subsection{Anomic Hero theme}

The Anomic Hero theme is characterised by low potency and low intimacy and contains 19 of the 74 content variables. This theme in agreement with life stressors and the result absence of meaning described by Durkheim (1951) and, in this case, by suicide as 
the method, the conquering of challenges symbolic of the hero narrative role (Youngs \& Canter, 2011). In this narrative theme, the suicide note writer fits the victim role of 'vehicle', as depicted in the tragedy and quest narratives of Canter (1994).

The content characteristics of this theme are those concerned with constructing the decision to die, through outlining the method (v11) and the indication that suicide has been planned for some time (v14). Low potency is implied through comments about intolerance or despondency (v30), the writer expressing their wish that there was a different solution (v24) or wishing that their ideal solution was attainable (v21), having tried to persevere (v43) and also by the mention of drug/alcohol dependency (v29), medical problems (v25) or elaborate physical pain (v45) as the explanation for suicide.

There is minimal reference to intimacy in this theme, though writers do express thanks (v56), which is the only content variable in this theme under the characteristic of constructing others. The use of metaphors (v73) implies a more sophisticated linguistic structure to the notes which could be indicative of individuals choosing to be euthanised (Ioannou \& Debowska, 2014). It could be argued that such a characteristic aligns with the role of the hero, as might the suggestion by the writer that they possess a positive self-image (v38) and have come to the decision to commit suicide with no third-party involvement (v13).

This theme also has the practical feature of instructions about funeral arrangements (v2) and reference to professional opinions about suicide (v46). There are some variables within this theme that are less easy to interpret or explain, such as the decision to die seeming ambivalent (v9) and a reference to unidentified things or others (v74).

\subsection{Fatalistic Revenger theme}

This theme contains aspects of high potency and high intimacy and contains slightly 
fewer content variables than the hero theme $(N=16)$. As per Durkheim's (1951) fatalistic type, this theme is characterised by a lack of sense of self and the role of distress and blame characterising the revenger (Youngs \& Canter, 2011). In this narrative theme, the suicide note writer also fits the victim role of 'vehicle' (Canter, 1994).

High potency or the desire to establish power is implied by the writer here through references to previous suicide attempts (v12), the use of sarcasm (v65), expressions of anger (v69), the mitigation of self-blame and the negative construction of their partner (v62). However, it is juxtaposed against feelings of injustice (v52) in which the cruel world or fate has taken control and the feeling that their life no longer has purpose (v22). Others are significant for the writer in this theme, as implied by asking their audience questions (v8), offering reassurance (v72) and making references to memories or shared conversations (v23).

\subsection{Altruistic Professional theme}

This final theme corresponds to the area on the plot depicting high potency and low intimacy. There are only two content variables present here. For Durkheim (1951) this suicide type relates to observing group norms and values at the expense of one's own needs, an example of which is a suicide bomber. As the professional in the narrative, this individual is calm and in competent charge of their environment (Youngs and Canter, 2011). In this narrative theme, the suicide note writer also fits the victim role of 'object' (Canter, 1994).

High potency is implied here by the suicide note writer referring to full acceptance of the decision to die (v34). Intimacy appears low as there is an obvious absence of any variables relating to others or the significance of others. The variable other (v33) appears in this region, referring to reasons other than the explanations listed in the content dictionary as the explanation for suicide. It is therefore possible that giving life for a cause — as per Durkheim's (1951) 
altruistic suicide type — could be a reason. Equally, the calm competence of the professional in Youngs and Canter's (2011) narrative role could be reflected in the implication that the decision to die is fully internalised, indicative of no inner conflict about the impending course of action. Notwithstanding these points though, very few suicide notes fall into this category so it is acknowledged that this theme is less established than the others.

\section{Discussion}

The aim of the study was to examine the potential of creating a model of differentiation in completed suicides based upon the content of their suicide notes. Four different themes of completed suicides were discovered based on the characteristics of their suicide notes. These four themes of Egoistic Victim, Anomic Hero, Fatalistic Revenger and Altruistic Professional align with the narrative roles proposed by Youngs and Canter (2011) in terms of potency and intimacy dimensions in offender narrative roles and, further, they correspond broadly with the suicide types proposed by Durkheim (1951).

The findings in the present study support those of Synnott, et al (2017), who found that most suicide notes corresponded with egoistic and anomic suicides, with some fitting into the category of fatalistic suicide but very few demonstrating the characteristics of suicide driven by altruism. The findings provide a useful insight into the mind of the suicide completer (O’Connor, et al, 1999) and thus provide a basis for proactive and therapeutic work with survivors of suicide or those contemplating suicide.

The discovery of narrative themes in completed suicides means that the criticism of the ideographic nature of suicide research, as mentioned by O'Connor, et al (1999) is not substantiated in the present study, which has shown that analysis of suicide notes can contribute to our understanding of suicide as both a social and group occurrence. 


\subsection{Previous research}

There was evidence to support the finding that suicide notes serve as an important final act of communication as opposed to merely an indicator of the mental state of the individual (McClelland, et al 2000, Sanger \& McCarthy Veach, 2008). The implied intention by suicide note writers to either preserve existing relationships or repair ones that have broken down, particularly in the Egoistic Victim theme, lends support to Giles' (2007) theory that suicide notes are ultra-social as well as extremely personal in nature (Leenaars, 1996). In line with Giles’ apologetic framework (2007) and the findings of Ioannou and Debowska (2014), apologies and expressions of love were present in over $30 \%$ of the suicide notes, which suggests that it was of importance to some note writers to indicate positive aspects of their relationships and to make amends with significant people.

However, not all suicide notes in this research were concerned with providing comfort to others or beseeching forgiveness, similar to the results of Lazarides, Wassenaar and Sekhesa (2019) where they identified the theme of anger and rage in the suicide notes they examined. There were elements, particularly in the Fatalistic Revenger theme, of dealing with unfinished business. Indeed, writers in this theme tended to construct their partner in a negative light or use anger or sarcasm as a way of communicating. This highlights that even if the intention of some of these ultimate forms of communication was not to reach out to people with acts of contrition or expressions of love, they were nonetheless an important final way for the note writer to connect with their audience.

Located within the Egoistic Victim theme were characteristics of loneliness or isolation, reference to future events that the writer wished to avoid and the characteristic of escape, which reflects the escapist imago as described by McAdams (1985) and supports the research of 
Edelman \& Renshaw (1982) who postulate that suicidal individuals have a strong sense of isolation from the world. In their study, evidence of isolation was borne out by a lack of any references to the future in suicide notes. The findings of the present study suggest that, rather than avoiding any references to the future, note writers had a clear perception of their future but it was one which was unacceptable as it presented a continuation of their present situation.

Perhaps unsurprisingly, notes writers often perceived suicide as their only option. Constricted thinking was a major theme — present in a quarter of suicide notes — which reaffirms previous findings in suicide research (Schneidman,1996, Leenaars, 1996, O'Connor, et al 1999, Chavez- Hernandez, Paramo, Leenaars, \& Leenaars, 2006) as well as research into narrative roles in offending (Ioannou, 2006; Youngs \& Canter, 2009, Ioannou, Canter \& Youngs, 2017; Ioannou, Synnott, Lowe \& Tzani-Pepelasi, 2018).

Self-mitigation, a key theme in the study of genuine suicide notes by Ioannou and Debowska (2014), was most commonly found in the Fatalistic Revenger theme and was located close to negative construction of partner. Though critiqued by Sanger and McCarthy Veach (2008) for their somewhat narrow view of focusing on blame management in suicide notes, McClelland, et al (2000) assert that the negotiation of blame is an important element of the discourse of suicide notes. The present study found that the requirement by the writer to absolve others of blame or responsibility was most likely to be found in the Egoistic Victim theme where potency was low, but others were significant for the note writer. Interestingly though, whilst blame was directed away from the partner here, negative constructions of the partner and mixed feelings towards them were also present in this theme. indicative perhaps of confusing cognitive distortions for the writer. Such distortions are explained by Youngs and Canter (2012) as a means of refocusing impact to fit with the ultimate objective. 
The inclination to combine a negative self-image with a concern for others (Synnott et al, 2017) was similarly found in this study, again in the Egoistic Victim theme. Here, note writers warned others of what they might find and asked that the fact that they had committed suicide be concealed from others. Whilst this could be construed as a way of protecting others, the latter could also be viewed as a form of self-preservation for the suicide completer.

Langer et al (2008) found that the suicide case files they studied were not lacking in agency; the paradox they discovered was that whilst agency was discernible in the files, the intention of the 'actors' was to play down agency and therefore defer blame. Similarly, McClelland et al (2000) posit that mitigating self-blame on the part of the suicide note writer serves to defend the act of suicide. Thus, being perceived as lacking agency is important to the writer in order to highlight not only the rationality but also the inevitability of committing suicide. In other words, people who succeed in committing suicide do not make the choice of not continuing their life — they are simply unable to continue.

The assertion of Youngs and Canter (2012) is that low potency in offending relates to assigning responsibility to others by assigning circumstances to fate. In the present study, note writers in the Fatalistic Revenger theme implied high potency through self-mitigation and expressions of injustice. In other words, they were able to express potency by assigning blame for suicide, not to themselves, but to fate or through negatively constructing their partner. Those in the low potency theme of Egoistic Victim were the individuals most concerned with a negative self-image, mitigating others, representing themselves as a martyr and displaying constricted thinking.

The present study displays partial reaffirmation of the themes of criminal narrative experience elucidated by Ioannou et al, (2016). Their distressed revenger was also characterised 
by anger and retaliation and their depressed victim by constriction and inevitability. The Professional's contentedness is implied and it is mirrored in the present study by the note writer in the Altruistic Professional theme, in which the individual has internalised the decision to die. There is perhaps less of a connection, though, with the emotions of their tragic hero who is personified by exhilaration and manliness.

Youngs and Canter (2011) justify use of the Victim, Hero, Revenger and Professional roles in offender narratives as they "capture the intention to act that is the essential component that drives a narrative construction" (p.247), as opposed to focusing on other motivations or external influences. Relying on these narrative themes, the present study has provided us with a better understanding of the act of suicide through an appreciation of the inner narrative of the suicide note writer. Criminal narratives are important because they link an actor to their actions (Ioannou, et al 2015), and this study suggests that the same can be said for completed suicides.

\subsection{Limitations}

Demographics were not factored into the present study as this information was not available in all cases. This therefore has implications for generalisability to the wider population. Researchers have previously raised questions about the generalisability of suicide note research in relation to suicide generally (Gottschalk \& Gleser, 1960, McClelland et al, 2000) in terms of those who leave a suicide note being representative of all suicides. Suicide notes are not the norm, a minority of individuals that take their own life leave notes, the percentages varies from 3\% to $42 \%$ (Chavez- Hernandez, et al., 2006; Demirel, Akar, Sayin, Candansayar, \& Leenaars, 2008; Eisenwort et al., 2007; Goren, Subasi, Tirashi, \& Ozen, 2004; Koronfel, 2002; Kuwabara et al., 2006; Wong, Yeung, Chan, Yip, \& Tang, 2009). However, work with suicidal individuals using a narrative roles approach may help to minimise generalisability issues to some extent. 
Many studies focusing on suicide notes have relied upon the same published corpora that were written in a different era. Though Sanger and McCarthy Veach (2008) postulate that this is not particularly problematic, it would perhaps be limiting to suicide research not to carry out studies using more current suicide notes, as the present study has done, but this is not without its limitations. Having used the same approach as Synnott et al (2017) of retrieving suicide notes from the Suicide Project website, the current study encountered the same issue regarding completed suicides. It is impossible to know if individuals who did not leave a subsequent entry in the two years following their suicide note did in fact die by their attempt. As these researchers suggested, this is a methodological flaw, but it is one that researchers must face when dealing with suicide note data, particularly in the era of the internet and social media.

\subsection{Implications and future research}

Despite the limitations, this project has some valuable insights regarding suicide notes, the suicide victims and their characteristics. Along similar lines to the work with offenders on criminal narrative experience carried out by Ioannou, et al (2017), therapeutic work could be carried out in clinical settings with suicide survivors and those with suicidal ideation that combines the narratives roles they assign to themselves with their emotions. Targeted work using cognitive behavioural therapy could then be conducted with individuals based upon the underlying narrative roles of completed suicides proposed in the current study. Suicide notes could also be used in a therapeutic role to help the surviving families and friends to understand why the loved one made this choice and to help others with information about suicide prevention strategies (Ho et al., 1998).

Given that rates of male suicide are consistently higher than female suicide, it may be useful to conduct specific narrative research that differentiates by gender in the context of suicide 
narrative roles. Coster and Lester (2013) made important discoveries of gender differences in respect of hurt cognitions following relationship breakdowns and links to suicide. It would therefore be useful to explore if there are gender differences in suicide in relation to the narrative roles of victim, hero, revenger and professional and apply such findings to practical therapy work as appropriate.

\subsection{Conclusion}

The present study has provided a useful basis upon which to explore future therapeutic work in suicide prevention which seems more important than ever. Using the characteristics found in the notes of those who died by their suicide attempts, this research has made important discoveries about how perceptions of power and intimacy and the cognitive approach to life struggles can shape outcomes for individuals. Exploration of inner narratives has connected individuals to their actions in the context of suicide - demonstrating that the story of death, when someone chooses to end their own life, can be explained by understanding the narrative of their life explicated through the words used in their final farewell. 


\section{References}

Abbas, M. J., Mohanna, M. A., Diab, T. A., Chikoore, M., \& Wang, M. (2018). Why Suicide? The Analysis of Motives for Self-Harm. Behavioural and cognitive psychotherapy, 46(2), 209-225.

Baechler. J. (1979). Suicides. New Yok Basic Books.

Borg, I., \& Lingoes, J. C. (1987). Facet Theory: Form and Content. New York: Springer Verlag.

Canter, D. (1994). Criminal shadows. London: Harper Collins.

Canter, D. \& Fritzon, K. (1998). Differentiating arsonists: A model of firesetting actions and characteristics. Legal and Criminal Psychology, 3, 73-96.doi:doiorg.libaccess.hud.ac.uk/ 10.1111/j.2044-8333.1998.tb00352.x.

Canter, D. \& Youngs, D. (2009). Investigative psychology: Offender profiling and the analysis of criminal action. Chichester: Wiley.

Callanan, V., \& Davis, M. (2009). A comparison of suicide note writers with suicides who did not leave notes. Suicide and Life-threatening Behavior, 39, 558-568.

doi:10.1521/suli.2009.39.5.558

Cerel, J., Moore, M., Brown, M., van der Venne, J., \& Brown, S. (2014). Who leaves suicide notes? A six-year population-based study. Suicide and Life-threatening Behavior, 45, 326334. doi:10.1111/sltb.12131

Ciesla, K., Ioannou, M., \& Hammond, L. (2019). Women Offenders' Criminal Narrative Experience. Journal of Criminal Psychology. 
Chávez-Hernández, A., Leenaars, A. A., Chávez-de Sánchez, M., \& Leenaars, L. (2009). Suicide notes from Mexico and the United States: A thematic analysis. Salud Publica de Mexico, 51(4), 314-320. Retrieved from http://library.hud.ac.uk/summon.

Chavez-Hernandez, A. M., Paramo, D., Leenaars, A. A., \& Leenaars, L. (2006). Suicide notes in Mexico: What do they tell us? Suicide and Life Threatening Behavior, 36, 709-715.

Coster, D. \& Lester, D. (2013). Last Words: Analysis of Suicide Notes from an RECBT Perspective: An Exploratory Study. Rational-Emotive Cognitive-Behavioral Therapy, (31), 136-151. doi: 10.1007/s10942-013-0166-z.

Demirel, B., Akar, T., Sayin, A., Candansayar, S., \& Leenaars, A. A. (2008). Farewell to the world: Suicide notes from Turkey. Suicide and Life-Threatening Behavior, 38, 122-127

Durkheim, E. (1951). Suicide: A study in sociology. Norfolk: Thetford Press.

Edelman, A.M. \& Renshaw, S.L. (1982). Genuine versus simulated suicide notes: An issue revisited through discourse analysis. Suicide and life-threatening behaviour, 12 (2), 103 113. doi: 10.1111/j.1943-278X.1982.tb00917.x.

Eisenwort, B., Berzlanovich, A., Heinrich, M., Schuster, A., Chocholous, P., Lindorfer, S., .. . Sonneck, G. (2007). Suicidology: Suicide notes and their themes. Nervenarzt, 78, 672, 674678

Ellis, T. E. (1988). Classification of suicidal behavior: A review and step toward integration.

Fritzon, K. \& Garbutt, R. (2001). A fatal interaction: The role of the victim and function of aggression in intrafamilial homicide. Psychology, Crime \& Law, 7 (1-4), 309-331. doi: 10.1080/10683160108401800.

Frye, N. (1957). Anatomy of criticism: Four essays. Princeton: Princeton University Press.

Giles, S. P. (2007). The final farewell: Using a narrative approach to explore suicide notes as ultra-social phenomenon, University of Liverpool, UK (Unpublished Doctoral Dissertation). 
Goodlad, K., Ioannou, M., \& Hunter, M. (2019). The criminal narrative experience of psychopathic and personality disordered offenders. International journal of offender therapy and comparative criminology, 63(4), 523-542.

Goren, S., Subasi, M., Tirashi, Y., \& Ozen, S. (2004). Female suicides in Diyarbakir, Turkey. Journal of Forensic Sciences, 49, 796-798.

Gottschalk, L.A. \& Gleser, G.C. (1960). An analysis of the verbal content of suicide notes. British Journal of Medical Psychology, 33 (3), 195-204.

Ho, T. P., Yip, P. S. F., Chiu, C. W. F., \& Halliday, P. (1998). Suicide notes: What do they tell us? Acta Psychiatrica Scandinavica, 98, 467-473

Ioannou, M. (2006). Hero or villain? Criminals' experience of crime. (PhD thesis). University of Liverpool, Liverpool.

Ioannou, M., Canter, D., Youngs, D., \& Synnott, J. (2015). Offenders' crime narratives across different types of crimes. Journal of Forensic Psychology Practice, 15 , 383-400. doi:10.1080/15228932.2015.1065620.

Ioannou, M., Canter , D., \& Youngs, D. (2017). Criminal narrative experience: Relating emotions to offence narrative roles during crime commission. International Journal of Offender Therapy and Comparative Criminology, 1-23. doi: 10.1177/0306624X15625991.

Ioannou, M., Hammond, L., \& Simpson, O. (2015). A model for differentiating school shooters characteristics. Journal of Criminal Psychology, 5(3), 188-200. DOI: 10.1108/JCP-062015-0018.

Ioannou, M. \& Debowska, A. (2014). Genuine and simulated suicide notes: An analysis of 
content. Forensic Science International, 245, 151-160. doi: 10.1016/j.forsciint. 2014.10.035.

Ioannou, M. \& Oostinga, M.S.D. (2016). An empirical framework of control methods of victims of human trafficking for sexual exploitation. Global Crime, 16 (1), 34-49.

Ioannou, M., Synnott, J., Lowe, E. \& Tzani-Pepelasi, C. (2018). Applying the criminal narrative experience framework to young offenders. International Journal of Offender Therapy and Comparative Criminology, 1-17.

Ioannou, M., Synnott, J., Reynolds, A. \& Pearson, J. (2018). A comparison of online and offline grooming characteristics: An application of the victim roles model. Computers in Human Behavior. DOI: 10.1016/j.chb.2018.04.011.

Kim, K., Choi, S., Lee, J., \& Sea, J. (2019). Differences in linguistic and psychological characteristics between suicide notes and diaries. The Journal of general psychology, 126.

Koronfel, A. A. (2002). Suicide in Dubai, United Arab Emirates. Journal of Clinical Forensic Medicine, 9, 5-11

Kuwabara, H., Shioiri, T., Nishimura, A., Abe, R., Nushida, H., Ueno, Y., . . Someya, T. (2006). Differences in characteristics between suicide victims who left notes or not. Journal of Affective Disorders, 94, 145-149.

Langer, S., Scourfield, J., \& Fincham, B. (2008). Documenting the quick and the dead: a study of suicide case files in a coroner's office. The Sociological Review, 56 (2), 293-308. doi: doi-org.libaccess.hud.ac.uk/10.1111/j.1467-954X.2007.00789.x

Lazarides, A., Wassenaar, D. R., \& Sekhesa, T. (2018). A thematic content analysis of suicide notes from South Africa. South African Journal of Psychology, 0081246318780144. 
Lee, Y. H., \& Joh, G. (2019). Identifying Suicide Notes Using Forensic Linguistics and Machine Learning. 언어학, 27(2), 171-191.

Leenaars, A. A. (1992). Suicide notes, communication and ideation. In R. W. Maris, A. L. Berman, T. Maltsberger, \& R. I. Yufit (Eds.), Assessment and prediction of suicide (pp. 337-355). New York, NY: Guilford Press.

Leenaars, A. (1996). Suicide: A multidimensional malaise. Suicide and Life-threatening Behavior, 61, 221-235.

Leenaars, A. (1998). Suicide notes: Predictive clues and patterns. New York: Human Sciences Press.

Lester. D. (1994). A comparison of 15 theories of suicide. Suicide and Life-Threatening Behavior. 24.80-88.Lingoes, J. C. (1973). The Guttman-Lingoes nonmetric program series. Ann Arbor: Mathesis Press.

McAdams, D.P. (1985). Power, intimacy and the life story. New York: Guildford Press.

McAdams, D.P. \& McLean, K.C. (2013). Narrative identity. Current Directions in Psychological Science, 22 (3), 233-238. doi: 10.1177/0963721413475622.

McLelland, L., Reicher, S., \& Booth, N. (2000). A last Defence: The negotiation of blame within suicide notes. Journal of Community \& Applied Social Psychology, 10 , 225-240. doi: doi-org.libaccess.hud.ac.uk/10.1002/1099-1298(200005/06)10:3<225::AIDCASP573>3.0.CO;2-1.

Niederkrotenthaler, T., Till, B., \& Garcia, D. (2019). Celebrity suicide on Twitter: Activity, content and network analysis related to the death of Swedish DJ Tim Bergling alias Avicii. Journal of affective disorders, 245, 848-855. 
O’Connor, R.C., Sheehy, N.P., \& O’Connor, D.B. (1999). A thematic analysis of suicide notes. Crisis, 20 (3), 106-114. doi: 10.1027//0227-5910.20.3.106.

O’Donnell, I., Farmer, R., \& Catalan, J. (1993). Suicide notes. British Journal of Psychiatry, 163, 45-48.Reynolds, F. M., \& Berman, A. L. (1995). An empirical typology of suicide. Archives of suicide research, 1(2), 97-109.

Pennebaker, J. W. (1993). Putting stress into words: Health, linguistic, and therapeutic implications. Behaviour research and therapy, 31(6), 539-548.

Pennebaker, J. W., Boyd, R. L., Jordan, K., \& Blackburn, K. (2015). The development and psychometric properties of LIWC2015. Austin, TX: University of Texas at Austin.

Salfati, G. (2000). The nature of expressiveness and instrumentality in homicide: Implications for offender profiling. Homicide Studies, 4 (3), 265-293. Retrieved from http://libray.hud.ac.uk/summon.

Samaritans. (2018). Suicide: Facts and figures. Retrieved from https://www.samaritans.org.

Sanger, S. \& McCarthy Veach, P. (2008). The interpersonal nature of suicide: A qualitative investigation of suicide notes. Archives of Suicide Research, 12 (4), 352-365. doi: $10.1080 / 13811110802325232$.

Shneidman, E.S. \& Farberow, N.L. (Eds.) (1957). Clues to suicide. New York: McGraw-Hill Book Company.

Shneidman, E. S. (1993). Suicide as psychache: A clinical approach to self-destructive behavior. Lanham, MD: Jason Aronson.

Stack, S., \& Rockett, I. (2016). Are suicide note writers representative of all suicides? Analysis of the national violent death reporting system. Suicide and Life-threatening Behavior. DOI: $10.1111 /$ sltb.12320 
Synnott, J., Ioannou, M., Coyne, A., \& Hemingway, S. (2017). A content analysis of online suicide notes: Attempted suicide versus attempt resulting in suicide. Suicide and LifeThreatening Behavior, 1-12. doi: 10.1111/sltb.12398.

The suicide Project. (2013). My suicide note. Retrieved from https://suicideproject.org.

Wong, P. G., Yeung, A. W., Chan, W. S., Yip, P. S., \& Tang, A. K. (2009). Suicide notes in Hong Kong in 2000. Death Studies, 33, 372-381.

World Health Organization. (2016). Suicide factsheet. Retrieved March 21, 2019, from https://www.who.int/mental_health/suicide-prevention/en/.

WordPress. (2011). Durkheim's Four Types of Suicide. Retrieved from https:// chilenabravo.wordpress.com.

Yaneva, M., Ioannou, M., Hammond, L., \& Synnott, J. (2018). Differentiating Contract Killers: A Narrative-Based Approach. The Howard Journal of Crime and Justice. DOI: 10.1111/hojo.12243.

Youngs, D. \& Canter, D. (2009). An emerging research agenda for investigative interviewing: Hypotheses from the narrative action system. Journal of Investigative Psychology and Offender Profiling, 6, 91-99. doi: 10.1002/jip.105.

Youngs, D. \& Canter, D.V. (2011). Narrative roles in criminal action: An integrative framework for differentiating offenders. Legal and Criminological Psychology, 17, 233-249. doi: 10.1111/j.2044-8333.2011.02011.x.

Youngs, D. \& Canter, D.V. (2012). Offenders' crime narratives as revealed by the narrative roles questionnaire. International Journal of Offender Therapy and Comparative Criminology, 57 (3), 289-311. doi: 10.1177/0306624X11434577.

Youngs, D. \& Ioannou, M. (2013). A model of client-related violence against female street sex workers. Journal of Forensic Social Work, 3 (3), 244-260. 
Youngs, D., Ioannou, M., \& Eagles, J. (2016). Expressive and Instrumental Offending:

Reconciling the Paradox of Specialisation and Versatility. International Journal of Offender Therapy and Comparative Criminology, 60(4), 397-422.

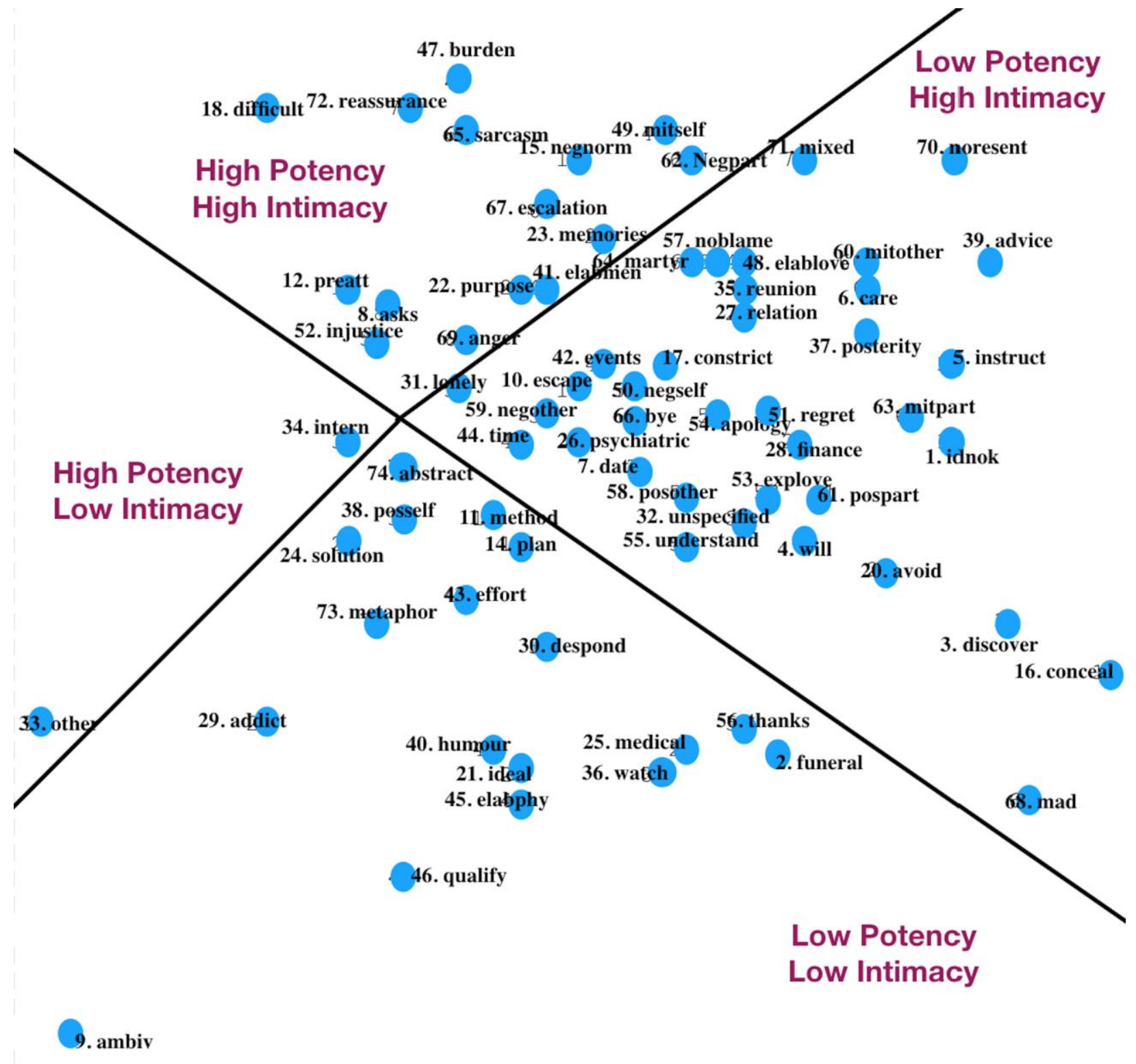

13. autonomy

Figure 1. Three-dimensional Smallest Space Analysis (SSA) plot of the 74 variables in 100 suicide notes with regions depicting potency and intimacy (co-efficient of alienation $=.17$ in 40 iterations). 


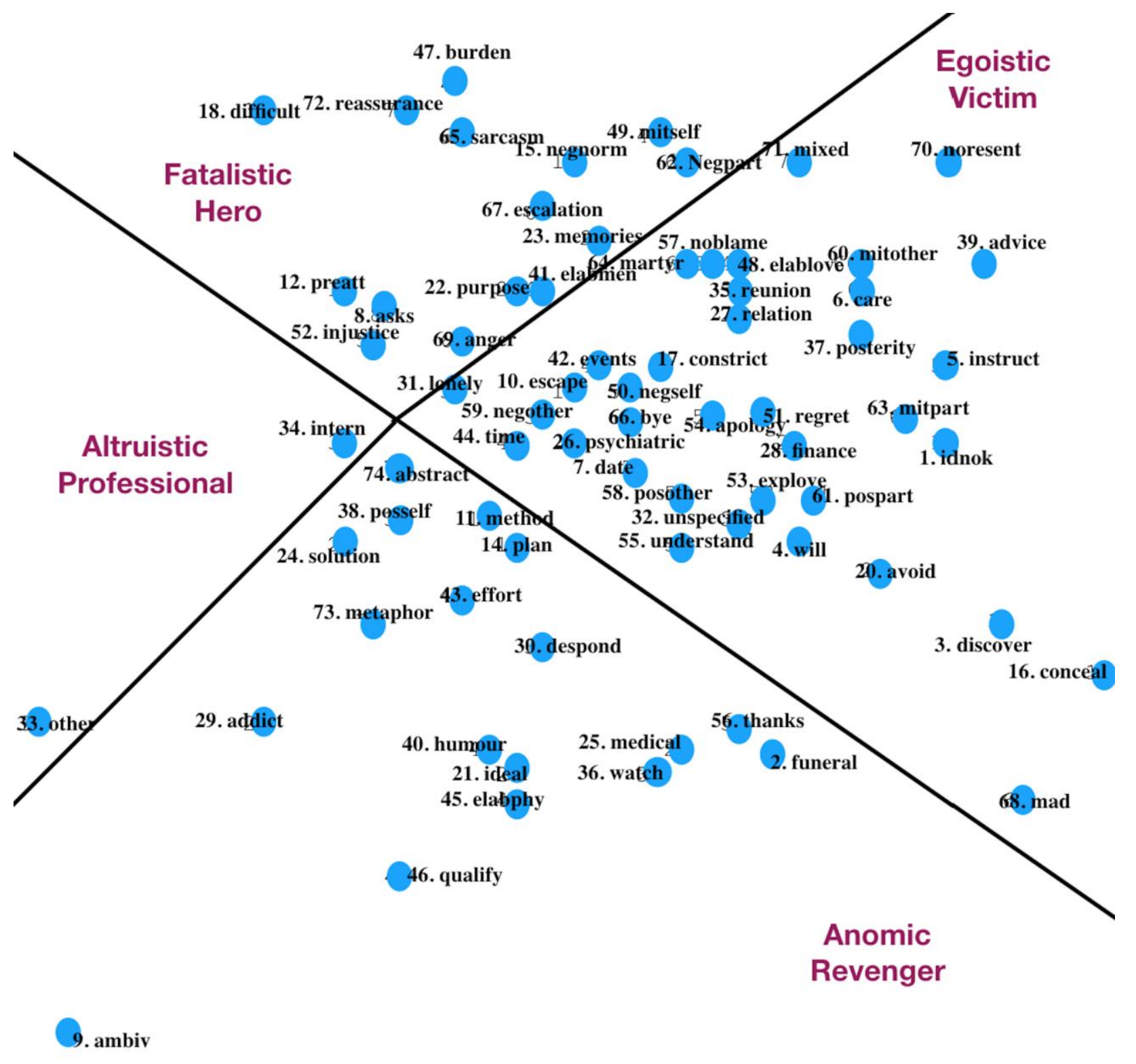

13. autonomy

Figure 2. Three-dimensional Smallest Space Analysis (SSA) plot of the 74 variables in 100 suicide notes with regions depicting narrative themes (co-efficient of alienation $=.17$ in 40 iterations). 


\section{Appendix 1}

\section{Content dictionary}

\begin{tabular}{|c|c|}
\hline Variable name & Label \\
\hline \multicolumn{2}{|l|}{ Practical features } \\
\hline 1. Idnok & Identify next of kin \\
\hline 2. Funeral & Instructions for funeral or body \\
\hline 3. Discover & Writer warns of what will be found \\
\hline 4. Will & Writer leaves will instructions \\
\hline 5. Instruct & Instructions left often emotional \\
\hline 6. Care & Leaves assurances or ask for financial care \\
\hline \multicolumn{2}{|c|}{ Constructing suicide and the decision to die } \\
\hline 7. Date & Note dated and signed \\
\hline 8. Asks & Writer asks audience questions \\
\hline 9. Ambiv & Decision to die appears ambivalent \\
\hline 10. Escape & Act is a form of escape from pain etc \\
\hline 11. Method & Writer mentions how suicide will be committed \\
\hline 12. Preatt & Writer mentions previous attempts to commit suicide \\
\hline 13. Autonomy & Writer states no third-party involvement \\
\hline 14. Plan & Writer indicates suicide planned for some time \\
\hline 15. Negnorm & Writer displays stereotypical thinking about suicide \\
\hline 16. Conceal & Asks addressee to conceal suicide from others \\
\hline 17. Constrict & Constriction: Suicide viewed as only option \\
\hline 18. Difficult & Decision construed as difficult or frightening \\
\hline 19. Rejects & Writer rejects any future narrative \\
\hline 20. Avoid & Reference to future events writer wants to avoid \\
\hline 21. Ideal & Sets out an ideal solution which is unobtainable \\
\hline 22. Purpose & Writer states life has no purpose \\
\hline 23. Memories & Refs to shared memories or past conversations \\
\hline 24. Solution & Writer wishes there was an alternative \\
\hline \multicolumn{2}{|l|}{ Constructing reason for suicide } \\
\hline 25. Medical & Writer mentions medical problems \\
\hline 26. Psychiatric & Reference to psychiatric problems or inner struggle \\
\hline 27. Relation & Reference to relationship problems or breakdown \\
\hline 28. Finance & Mention of financial problems \\
\hline 29. Addict & Reference to drug or alcohol dependency \\
\hline 30. Despond & Reference to drug or alcohol dependency \\
\hline 31. Lonely & Writer expresses loneliness or isolation \\
\hline 32. Unspecified & No explanation of why writer wants to commit suicide \\
\hline 33. Other & Other reasons given for suicide \\
\hline \multicolumn{2}{|l|}{ Constructing self } \\
\hline 34. Intern & Writer accepts decision to die and includes lack of regrets \\
\hline 35. Reunion & Writer alludes to reunion in the afterlife \\
\hline 36. Watch & Writer suggests will watch over loved ones \\
\hline 37. Posterity & Asks to be remembered \\
\hline 38. Posself & Constructs positive self-image \\
\hline 39. Advice & Writer offers advice \\
\hline 40. Humour & Writer uses humour \\
\hline 41. Elabmen & Refers to unbearable psychological pain \\
\hline 42. Events & Refers to events that led to suicide \\
\hline 43. Effort & Writer suggests having tried to persevere \\
\hline 44. Time & Writer implies longevity of problems \\
\hline 45. Elabphy & Refers to elaborate physical pain \\
\hline 46. Qualify & Suicide includes professional opinions \\
\hline 47. Burden & Writer suggests he has been a burden \\
\hline
\end{tabular}




\begin{tabular}{|c|c|}
\hline 48. Elablove & $\begin{array}{l}\text { Refers to elaborate love and relationship breakdown as } \\
\text { suicide reason }\end{array}$ \\
\hline 49. Mitself & Writer mitigates any self-blame \\
\hline 50. Negself & Portrays self in negative light \\
\hline 51. Regret & Writer mentions past regrets \\
\hline 52. Injustice & Refers to cruel world (life \\
\hline \multicolumn{2}{|l|}{ Constructing others } \\
\hline 53. Explove & Writer expresses love for audience \\
\hline 54. Apology & Writer says sorry or asks for forgiveness \\
\hline 55. Understand & Requests that recipient understands decision \\
\hline 56. Thanks & Writer expresses gratitude \\
\hline 57. Noblame & Writer asks audience not to be sad or blame themselves \\
\hline 58. Posother & Positively constructs others (not partner) \\
\hline 59. Negother & Negatively constructs others (not partner) \\
\hline 60. Mitother & Offers explanations so that others don't feel guilty \\
\hline 61. Pospart & Writer positively constructs partner \\
\hline 62. Negpart & Writer negatively constructs partner \\
\hline 63. Mitpart & Attempts to dilute any blame felt by partner \\
\hline 64. Martyr & Presents self as martyr whose death will benefit others \\
\hline 65. Sarcasm & Writer uses sarcastic comments \\
\hline 66. Bye & Writer says goodbye to audience \\
\hline 67. Escalation & Ref to escalation of events leading to suicide \\
\hline 68. Mad & Asks recipient not to think badly of them \\
\hline 69. Anger & Writer expresses anger or negativity \\
\hline 70. Noresent & Holds no resentment or forgives others \\
\hline 71. Mixed & Expresses mixed feelings twd partner (pos and neg) \\
\hline 72. Reassurance & Writer assures audience they will soon forget/move on \\
\hline \multicolumn{2}{|l|}{ Structure } \\
\hline 73. Metaphor & Writer uses metaphors \\
\hline 74. Abstract & Reference to unidentified things \\
\hline
\end{tabular}

\section{Appendix 2}

\section{Note from the Suicide Project website}

To Whom It May Concern...

If you are reading this than I am dead.

This may come as a shock to most who know me.

If you want to know why, it's basically because I hate myself. I've actually vomited because I hate myself so much. I loathe myself. I'm tired of being mediocore. I'm tired of being a failure to everyone around me. I'm never going to be handsome, or successful, or marry. My future is bleak, lonely and full of suffering.

So I've decided to let you all down one last time.

Since April, something hasn't been right and after campmeeting I found myself slipping into a black hole. I've done my upmost to put on a happy face and be a man, so I don't worry anyone.

I've tried to kill myself twice already and backed down.

Ever since August I've been on and off again depressed. And in November I made my decision to kill myself in January. Because nothing is really going on.

I figured out in August I have major depressive disorder.

I hate myself so much and I hate being such a wasted space.

I know there are people who care about me and who I will hurt but I just don't care.

I haven't felt anything good for too long. And even if it gets better, it will always get worse again. 
I don't want anyone to think this is their fault or feel guilty.

Just please don't hate me and please try to move on. With such a piece of trash like me it shouldn't take too long.

I'm just so sorry I could never be what anyone wants me to be or live up to anyone's expectations.

All I want to do is not exist.

I just want to be normal. But I know I can't and will never be.

I'm so sorry to hurt anyone but I will never hurt anyone again.

You will all be better off with me gone. I'm toa stupid and messed up to ever be happy. This is the only thing I want.

P.S. If I fail and wind up mentally disabled in any way, do not make any efforts to save me. I don't want to live that way.

\section{Note from published corpora}

Dearest Mary, This is to say goodbye. I have not told you because I did not want you to worry, but I have been feeling bad for 2 years, with my heart. I knew that if I went to a doctor I would lose my job. I think this is best for all concerned. I am in the car in the garage. Call the Police, but please don't come out there. I love you very much darling. Goodbye. 